\title{
Differences in Vase Lives of Cut Hydrangea Flowers Harvested at Different Developmental Stages
}

\author{
Yoshikuni Kitamura*, Sachiyo Ueno, Hiroe Aizawa and WeiWei Teoh \\ Faculty of Agriculture, Shinshu University, Minamiminowa, Nagano 399-4598, Japan
}

Two types of cut hydrangea flowers are marketed: Fresh-stage cut flowers (harvested just after the decorative sepals are completely colored before or during flowering) and antique-stage cut flowers (harvested when the decorative sepals become green and/or red after flowering). We investigated the differences in vase lives between fresh- and antique-stage cut flowers using 10 cultivars and 5 lines of hydrangea. The antique-stage cut flowers of 'Endless Summer', 'Glowing Alps', 'Grünherz', 'Masja', 'Temari Ezo', and line No.2 exhibited significantly longer vase lives than their fresh-stage cut flowers. The difference in vase lives between the cut flowers of 'Masja' harvested at two different stages was approximately 60 days. We conducted further studies to elucidate the contribution of detailed differences in the harvest stages to differences in the vase lives using 'Masja' and 'Xi'an'. Vase lives were compared among the cut flowers harvested at four different harvest stages that were divided based on flowering of florets and greening of the decorative sepals. The cut flowers of 'Xi'an' harvested at the decorative florets flowering- and decorative sepal greening-stages showed significantly longer vase lives than those harvested at the non-decorative floret flowering stage. The cut flowers of 'Masja' harvested at two harvest stages following the beginning of the decorative sepal greening stage exhibited significantly longer vase lives than those harvested at the other two harvest stages. A recutting treatment rescued the cut flowers harvested at the decorative sepal greening completed-stages that exhibited softening of the decorative sepals. This result suggested that the vase lives of cut hydrangea flowers were terminated by the disruption of water balance caused by vessel occlusion in the stem ends. In conclusion, a relatively longer vase life can be expected when cut hydrangea flowers are harvested after flowering of the decorative florets. However, we should note that cut flowers of some cultivars harvested at the decorative floret flowering stage may exhibit relatively short vase lives. Treatments that suppress vessel occlusion may be effective for lengthening the vase lives of cut hydrangea flowers.

Key Words: antique-stage, decorative sepal, fresh-stage, harvest stage, vessel occlusion.

\section{Introduction}

Hydrangeas (Hydrangea spp.) are popular ornamental plants cultivated in many countries, and demand for cut hydrangea flowers has been increasing in recent years. In Japan, approximately 640000 cut hydrangea flowers were handled in 2014 at the Ota Floriculture Auction, and this number increased to approximately 696000 in 2016. Hydrangea inflorescences have nondecorative florets that bear tiny sepals, and decorative florets that bear large decorative sepals. Hydrangea inflorescences are classified into two types based on the arrangement of these florets: hortensia and lacecap

Received; June 8, 2017. Accepted; November 10, 2017.

First Published Online in J-STAGE on December 20, 2017.

* Corresponding author (E-mail: hyphy281@shinshu-u.ac.jp).
(Uemachi and Nishio, 2005; Uemachi et al., 2006). Nearly all hydrangea cultivars in the cut flower market possess hortensia-type inflorescences. Hybrids of H. macrophylla and H. serrata are frequently used for cut flower production, and some of them flower throughout the growing period (Kitamura, 2016). In addition, some cultivars for pot flower production are also used for cut flower production. Two types of cut hydrangea flowers are marketed: fresh-stage cut flowers (harvested just after the decorative sepals are completely colored before or during flowering) and antiquestage cut flowers (harvested when the decorative sepals turn green and/or red after flowering) (Kitamura, 2016). Market staff and the growers of cut hydrangea flowers often believe that antique-stage cut hydrangea flowers have longer vase lives than fresh-stage cut hydrangea flowers. However, no study has examined differences in 
vase lives between these two types of cut hydrangea flowers.

Several studies have focused on decorative organs maintained after flowering, with one study that focused on hydrangea flowers (Melo et al., 1995; Salopek-Sondi et al., 2000, 2002; Schmitzer et al., 2013; Tavares et al., 1998; Yoshida et al., 2008). These studies reported on photosynthesis, the relationship between sepal retention and fruit development, and pigments. However, none of these studies reported on the vase lives of cut flowers.

In fresh-stage cut hydrangea flowers, defoliation, reduction in the decorative florets, and covering of the inflorescence are effective for extending vase lives. It has been suggested that these treatments extend vase lives by suppressing transpiration of the cut flowers (Kitamura and Ueno, 2015; Mega, 1957). In addition, transpiration of non-decorative floral organs regulates the vase lives of fresh-stage cut hydrangea flowers (Kitamura et al., 2017b). On the other hand, we previously reported that an increase in stomatal conductance is observed in antique-stage decorative sepals of many hydrangea cultivars (Kitamura et al., 2017a). Thus, suppression of transpiration from cut flowers would not be a factor for the longer vase lives observed in antiquestage cut hydrangea flowers.

In the present study, we compared vase lives between fresh- and antique-stage cut hydrangea flowers. Furthermore, we conducted a study to elucidate the contribution of the detailed differences in the harvest stages to the differences in vase lives. Lastly, we discussed the factors that regulate the vase lives of cut hydrangea flowers and some countermeasures to enhance their vase lives.

\section{Materials and Methods}

\section{Plant materials}

This study aimed to elucidate the difference in vase lives of cut flowers at different harvest stages among a wide variety of cultivars bred between or among H. macrophylla and H. serrata. Thus, several cultivars bred as garden shrubs were also used in the study. Ten horticultural cultivars and five hydrangea lines were used. 'Glowing Alps' and 'Xi'an' are cultivars bred for cut flower production in the Netherlands. 'Benton', 'Christmas', 'Endless Summer', 'Flambeau', 'Grünherz', 'Madame Emile Mouillere', and 'Masja' are cultivars used as garden shrubs, but we often find they are also used for cut flower production. These seven cultivars are hybrids between or among H. macrophylla and H. serrata. 'Endless Summer' and 'Xi'an' were purchased from a nursery. 'Glowing Alps' was obtained as cuttings from a farmer in 2010. The rest of the cultivars were obtained as cuttings from the Kyoto University experimental farm in May 2010. 'Temari Ezo' is an ancestor of the hydrangea horticultural cultivar, H. serrata, and was obtained from Shiga Prefectural University in 2007. Lines No. 1, 3, and 5 originated from cuttings obtained from commercially available cut flowers in 2010, but we could not identify the cultivar name. Lines No. 2 and 4 were obtained from garden shrubs planted at Kyoto University and Shinshu University in 2007 and 2010, respectively, and they are cultivars bred as garden shrubs. All lines used in this study are hybrids between or among H. macrophylla and H. serrata. The unidentified cultivars can be supplied to researchers who wish to conduct confirmatory experiments. At the Shinshu University experimental farm, all plants were grown in $32.5 \mathrm{~cm}$ diameter pots filled with $8 \mathrm{~L}$ medium consisting of $75 \%$ Metro Mix 250 (SunGro Horticulture, Agawam, MA, USA) and 25\% vermiculite (v/v) (Asahi Kogyo, Okayama, Japan) from December to March in a greenhouse maintained above $0^{\circ} \mathrm{C}$. Plants were grown under full sunlight from December to May, under $70 \%$ sunlight from June to July, and under $50 \%$ sunlight from July to August. Dio Cool White (Dio Kasei, Tokyo, Japan) $420 \mathrm{SW}$ (30\% shading) and $620 \mathrm{SW}$ (50\% shading) were used.

Harvest, preparation, and vase life of fresh- and antique-stage cut flowers

From June to July in 2014, four to nine fresh-stage cut flowers with approximately $60 \mathrm{~cm}$ stems were harvested just after approximately $80 \%$ of the decorative florets in the inflorescence had developed the cultivarspecific coloration of the decorative sepals. From July to August in 2014, four to seven antique-stage cut flowers with approximately $60 \mathrm{~cm}$ stems were harvested just after approximately $80 \%$ of the decorative florets in the inflorescence had turned green and/or red. Between the two stages, inflorescences considered to have almost identical numbers of decorative florets were harvested. All cut flowers were defoliated just after harvest.

Leaving $50 \mathrm{~cm}$ stems, the end of the cut flower stem was recut under distilled water just after harvest. All cut flowers were kept in plastic bottles filled with $1 \mathrm{~L}$ of distilled water. Distilled water was appropriately added during the study period. Recutting of the stem end or water exchange were not conducted during the study. The bottle was loosely sealed with parafilm (Pechiney Plastic Packaging Company, Chicago, IL, USA) to suppress evaporation from the water surface. Cut flowers were placed in an environment-controlled room at $25 \pm$ $2{ }^{\circ} \mathrm{C}$ and $50 \pm 5 \%$ relative humidity ( $\left.\mathrm{RH}\right)$, and maintained under $12 \mathrm{~h}$ photoperiods at a light intensity of $10 \mu \mathrm{mol} \cdot \mathrm{m}^{-2} \cdot \mathrm{s}^{-1}$ provided by daylight fluorescent tubes (FL40SSN/37; Toshiba Lighting and Technology Co., Yokosuka, Japan).

Vase life was terminated when withering, sepal browning, or sepal desiccation became apparent on approximately $80 \%$ of decorative florets in an inflorescence based on daily observations (Fig. 1). Decorative florets were counted after the end of the vase life. Our previous study showed that the stem diameters are 
almost identical between cut flowers bearing similar numbers of decorative florets (Kitamura and Ueno, 2015). Therefore, the stem diameters of cut flowers were not investigated in this study.

\section{Vase life of the cut flowers harvested at different harvest stages}

The differences in the vase lives of the cut flowers harvested at four different harvest stages were compared using 'Masja' and 'Xi'an' (Fig. 2). Antique-stage cut flowers of these cultivars had the longest vase lives of the studied cultivars, and we thought that they would be suitable for studying the differences in vase lives among the four harvest stages as follows. In hydrangea inflorescence, non-decorative florets flower before flowering of the decorative florets. Cut flowers at the fresh-stage include cut flowers in the non-decorative florets flowering- and decorative florets floweringstage. In this study, we classed these two floret flower-



Fig. 1. Appearances of fresh- and antique-stage cut flowers at the end of their vase lives. (A) Wilting of a fresh-stage cut flower with shrinking of decorative sepals. (B) Browning of decorative sepals. (C) Desiccation of decorative sepals without shrinking observed in antique-stage cut flowers. ing stages as two different harvest stages: Stage 1, almost non-decorative florets flowering; stage 2, approximately $80 \%$ of decorative florets flowering. In addition, harvest stages from stage 2 to the antique-stage were subdivided into two harvest stages: Stage 3, beginning of the decorative sepal greening in $50 \%$ of decorative florets; stage 4, decorative sepal greening completed. Stage 4 is equivalent to the antique-stage. Based on observations of both cultivars in our field conditions, stage 2 was defined as 10 days after stage 1 , stage 3 was defined as 18 days after stage 2, and stage 4 was defined as 16 days after stage 3 . From July to August in 2016, 5-11 cut flowers at each of the four different stages were harvested. Cut flowers were prepared and vase life was determined as mentioned above.

Using three 'Xi'an' cut flowers harvested at stage 4, the weight of the cut flowers was measured every day, and relative weights of cut flowers to those of harvest day were calculated. When the decorative sepals softened due to decreasing turgor (a sign of the beginning of decorative sepal desiccation), $2 \mathrm{~cm}$ of stem ends of the cut flowers were recut in distilled water. Weights of the stem ends were recorded and added to the weight of cut flowers after the recut treatment. The study was continued for four days after the recut treatment.

\section{Statistical analyses}

Data collected for vase life and number of decorative florets of fresh- and antique-stage cut flowers were ana-


Fig. 2. The four harvest stages of cut flowers, based on the flowering of the florets and greening of the decorative sepals. Upper: 'Masja', lower: 'Xi'an'. Stage 1, flowering of almost all non-decorative florets; stage 2, flowering of approximately $80 \%$ of decorative florets; stage 3, beginning of decorative sepal greening in $50 \%$ of decorative florets; stage 4, completion of decorative sepal greening. Stages 1 and 2 are equivalent to the fresh-stage. Stage 4 is equivalent to the antique-stage. Days required for the transition to the next harvest stage are indicated on the plates. 
lyzed using $t$-tests. Significance of correlation between vase lives of fresh- and antique-stage cut flowers was analyzed by calculating Pearson's correlation coefficient. Data collected for vase life of cut flowers harvested at four different stages were analyzed using Tukey's multiple range test.

\section{Results}

Vase life prolonged in antique-stage cut flowers compared with fresh-stage cut flowers in six cultivars

The vase life of fresh-stage cut flowers varied by cultivar and ranged from 7.0 to 28.5 days, while those of antique-stage cut flowers ranged from 9.0 to 71.6 days. No significant correlation was observed between the vase lives of fresh- and antique-stage cut flowers $(r=$ $0.212, P=0.466)$. The vase lives of antique-stage cut flowers of 'Endless Summer', 'Glowing Alps', 'Grünherz', 'Masja', 'Temari Ezo', and line No. 2 were significantly longer than those of fresh-stage cut flowers (Table 1). The difference in vase life was greatest for 'Masja', at approximately 60 days. Vase life of antique-stage cut flowers of 'Benton', 'Christmas', 'Masja', 'Xi'an', line No.2, line No. 3, and line No. 4 varied widely. In particular, 1, 1, 2, 2, 3, 1, and 2 antique-stage cut flowers of these cultivars achieved more than 80 days of vase life, respectively, and they developed roots on the end of the stem without exception. In those cut flowers, the vase water became turbid. However, stem end rot was not observed in those cut flowers. On the other hand, the remaining antique-stage cut flowers of these cultivars showed a vase life of less than 40 days, and root development was not observed. Some of them showed almost identical or shorter vase lives than fresh-stage cut flowers. Antique-stage cut flowers of 'Flambeau', 'Madame Emile Mouillere', and line No. 1 showed almost identical vase lives to the fresh-stage cut flowers. In 'Benton', 'Christmas', 'Xi' an', line No. 3, line No. 4, and line No. 5, vase lives in fresh- and/or antique-stage cut flowers were highly variable, and no significant difference in vase life was found between the two stages. The number of decorative florets in the inflorescence did not differ between fresh- and antique-stage cut flowers (Table 1).

Appearance at the end of vase life differed between fresh- and antique-stage cut flowers

In most of the antique-stage cut flowers, gradual desiccation of the decorative sepals marked the end of vase life (Fig. 1C; Table 2). In 'Masja', 'Xi'an', and line No. $5,83.3 \%, 80.0 \%$, and $100 \%$ of antique-stage cut flowers showed browning of decorative sepals toward the end of vase life, respectively. Except for 'Benton', 'Madame Emile Mouillere', 'Masja', line No.2, and No. 4, rapid wilting of the decorative sepals marked the end of vase life in $60.0 \%$ to $100 \%$ of the fresh-stage cut flowers (Fig. 1A, B; Table 2). In 'Madame Emile Mouillere' and 'Masja', $83.3 \%$ and $88.9 \%$ of freshstage cut flowers showed browning of decorative sepals toward the end of vase life, respectively. Desiccation of antique-stage decorative sepals was not accompanied by shrinkage, whereas wilting of fresh-stage decorative sepals was invariably accompanied by shrinkage.

Table 1. Numbers of decorative florets per cut flower, vase life, and number of rooted cut flowers of fresh- and antique-stage cut flowers.

\begin{tabular}{|c|c|c|c|c|c|c|c|c|c|c|c|c|c|c|}
\hline \multirow{3}{*}{ Cultivar and line } & \multicolumn{2}{|c|}{$\begin{array}{l}\text { Number of cut } \\
\text { flowers studied }\end{array}$} & \multicolumn{3}{|c|}{ Number of decorative florets } & \multicolumn{6}{|c|}{ Vase life (days) } & \multicolumn{3}{|c|}{$\begin{array}{c}\text { Number of rooted cut } \\
\text { flowers }\end{array}$} \\
\hline & \multirow{2}{*}{ Fresh } & \multirow{2}{*}{ Antique } & \multirow{2}{*}{ Fresh $^{2}$} & \multirow{2}{*}{ Antique } & \multirow{2}{*}{$t$ - test $^{\mathrm{y}}$} & \multicolumn{3}{|c|}{ Fresh } & \multicolumn{3}{|c|}{ Antique } & \multirow{2}{*}{$t$-test } & \multirow{2}{*}{ Fresh } & \multirow{2}{*}{ Antique } \\
\hline & & & & & & Average & Min. & ${\text { Max. }{ }^{x}}^{x}$ & Average & Min. & Max. & & & \\
\hline Benton & 5 & 4 & $183.0 \pm 21.2$ & $141.3 \pm 7.2$ & NS & $13.2 \pm 4.0$ & 6 & 27 & $40.8 \pm 15.0$ & 20 & 85 & NS & 0 & 1 \\
\hline Christmas & 5 & 7 & $446.0 \pm 59.0$ & $429.7 \pm 53.1$ & NS & $11.4 \pm 1.2$ & 8 & 14 & $26.0 \pm 10.3$ & 11 & 87 & NS & 0 & 1 \\
\hline Endless Summer & 8 & 5 & $351.1 \pm 57.4$ & $304.5 \pm 41.1$ & NS & $11.0 \pm 1.4$ & 6 & 17 & $24.2 \pm 1.9$ & 18 & 31 & $*$ & 0 & 0 \\
\hline Flambeau & 4 & 5 & $68.0 \pm 1.7$ & $70.0 \pm 4.9$ & NS & $11.3 \pm 2.3$ & 6 & 15 & $9.0 \pm 0.4$ & 8 & 10 & NS & 0 & 0 \\
\hline Glowing Alps & 5 & 6 & $215.4 \pm 31.7$ & $209.5 \pm 29.9$ & NS & $14.2 \pm 0.7$ & 13 & 16 & $21.7 \pm 1.5$ & 17 & 27 & * & 0 & 0 \\
\hline Grünherz & 5 & 5 & $216.6 \pm 11.4$ & $162.6 \pm 7.1$ & NS & $7.0 \pm 1.8$ & 4 & 14 & $16.8 \pm 2.9$ & 8 & 25 & * & 0 & 0 \\
\hline Madame Emile Mouillere & 6 & 6 & $149.0 \pm 25.2$ & $178.3 \pm 16.0$ & NS & $20.3 \pm 4.3$ & 4 & 29 & $25.7 \pm 2.3$ & 15 & 31 & NS & 0 & 0 \\
\hline Masja & 9 & 6 & $213.2 \pm 31.2$ & $174.3 \pm 10.3$ & NS & $10.4 \pm 1.8$ & 6 & 20 & $70.3 \pm 22.7$ & 21 & 153 & * & 0 & 2 \\
\hline Temari Ezo & 4 & 4 & $396.5 \pm 56.3$ & $345.8 \pm 32.2$ & NS & $12.5 \pm 0.9$ & 10 & 14 & $45.0 \pm 11.1$ & 26 & 73 & $*$ & 0 & 0 \\
\hline Xi'an & 4 & 5 & $200.5 \pm 28.3$ & $197.8 \pm 20.5$ & NS & $14.3 \pm 0.4$ & 14 & 15 & $71.6 \pm 28.8$ & 23 & 144 & NS & 0 & 2 \\
\hline No. 1 & 5 & 6 & $246.8 \pm 47.3$ & $225.5 \pm 22.1$ & NS & $10.0 \pm 1.8$ & 6 & 11 & $12.3 \pm 0.5$ & 11 & 14 & NS & 0 & 0 \\
\hline No. 2 & 6 & 6 & $241.3 \pm 16.6$ & $307.5 \pm 55.0$ & NS & $12.5 \pm 2.0$ & 9 & 22 & $62.0 \pm 19.4$ & 14 & 120 & * & 0 & 3 \\
\hline No. 3 & 4 & 6 & $113.3 \pm 12.4$ & $145.0 \pm 27.5$ & NS & $28.5 \pm 4.4$ & 18 & 39 & $48.0 \pm 24.5$ & 14 & 142 & NS & 0 & 1 \\
\hline No. 4 & 6 & 6 & $286.7 \pm 28.7$ & $273.2 \pm 24.6$ & NS & $16.0 \pm 2.5$ & 11 & 27 & $62.5 \pm 27.4$ & 10 & 173 & NS & 0 & 2 \\
\hline No. 5 & 5 & 5 & $105.6 \pm 16.3$ & $136.0 \pm 5.4$ & NS & $18.2 \pm 4.4$ & 10 & 29 & $29.2 \pm 4.6$ & 15 & 36 & NS & 0 & 0 \\
\hline
\end{tabular}

z Means \pm SE.

$\mathrm{y} *$ and NS: significance at $P<0.05$ and non-significance by $t$-test.

${ }^{x}$ Minimum vase life and maximum vase life (day). 
Table 2. Comparison of the appearances of fresh- and antique-stage cut flowers at the end of their vase lives.

\begin{tabular}{|c|c|c|c|c|c|c|c|c|}
\hline \multirow[t]{2}{*}{ Cultivar and line } & \multicolumn{2}{|c|}{$\begin{array}{l}\text { Number of cut } \\
\text { flowers studied }\end{array}$} & \multicolumn{2}{|c|}{ Wilting (\%) } & \multicolumn{2}{|c|}{ Browning (\%) } & \multicolumn{2}{|c|}{ Desiccating (\%) } \\
\hline & Fresh & Antique & Fresh & Antique & Fresh & Antique & Fresh & Antique \\
\hline Benton & 5 & 4 & 40.0 & 0 & 40.0 & 0 & 20.0 & 100 \\
\hline Christmas & 5 & 7 & 80.0 & 0 & 20.0 & 14.3 & 0 & 85.7 \\
\hline Endless Summer & 8 & 5 & 75.0 & 0 & 25.0 & 20.0 & 0 & 80.0 \\
\hline Flambeau & 4 & 5 & 75.0 & 0 & 25.0 & 0 & 0 & 100 \\
\hline Glowing Alps & 5 & 6 & 60.0 & 0 & 40.0 & 0 & 0 & 100 \\
\hline Grünherz & 5 & 5 & 100 & 0 & 0 & 0 & 0 & 100 \\
\hline Madame Emile Mouillere & 6 & 6 & 16.7 & 0 & 83.3 & 0 & 0 & 100 \\
\hline Masja & 9 & 6 & 11.1 & 0 & 88.9 & 83.3 & 0 & 16.7 \\
\hline Temari Ezo & 4 & 4 & 75.0 & 0 & 25.0 & 25.0 & 0 & 75.0 \\
\hline Xi'an & 4 & 5 & 100 & 0 & 0 & 80.0 & 0 & 20.0 \\
\hline No. 1 & 5 & 6 & 100 & 0 & 0 & 0 & 0 & 100 \\
\hline No. 2 & 6 & 6 & 16.7 & 0 & 83.3 & 50.0 & 0 & 50.0 \\
\hline No. 3 & 4 & 6 & 75.0 & 0 & 25.0 & 33.3 & 0 & 66.7 \\
\hline No. 4 & 6 & 6 & 50.0 & 0 & 50.0 & 16.7 & 0 & 83.3 \\
\hline No. 5 & 5 & 5 & 100 & 0 & 0 & 100 & 0 & 0 \\
\hline
\end{tabular}

A
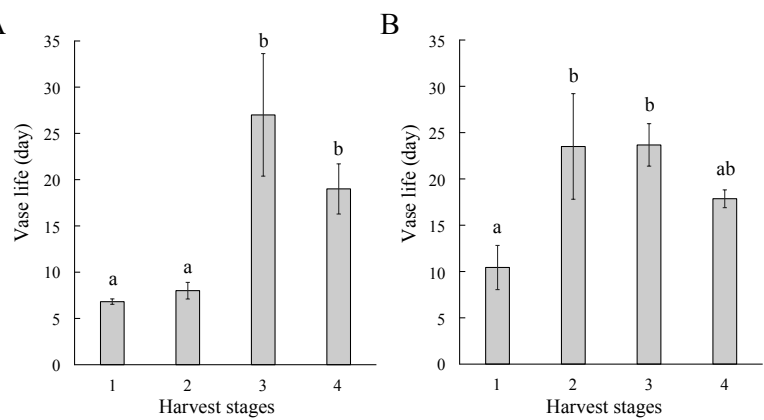

Fig. 3. Vase lives of the cut flowers harvested at four different harvest stages. A: 'Masja', B: 'Xi'an'. Stage 1, flowering of almost all non-decorative florets; stage 2, flowering of approximately $80 \%$ of decorative florets; stage 3, beginning of decorative sepal greening in $50 \%$ of decorative florets; stage 4 , completion of decorative sepal greening. Stages 1 and 2 are equivalent to the fresh-stage. Stage 4 is equivalent to the antique-stage. Different letters indicate that the values were significantly different according to Tukey's multiple range test at $P<0.05$. Bars indicate \pm SE $(\mathrm{n}=5-11)$.

Difference in the vase life among the harvest stages varied by cultivars

'Masja' cut flowers at two harvest stages after stage 3 showed significantly longer vase lives than the cut flowers at the other two harvest stages (Fig. 3A). In 'Xi'an', the cut flowers at stages 2 and 3 showed significantly longer vase lives than those harvested at stage 1 (Fig. 3B). Cut flowers of 'Xi'an' at stage 4 showed relatively longer vase life than those at stage 1 , but the difference was not significant.

Recutting of the stem end rescued the decrease in weight of cut flowers at stage 4

The weight of three cut flowers of 'Xi'an' harvested at stage 4 decreased over time, and recutting of the stem

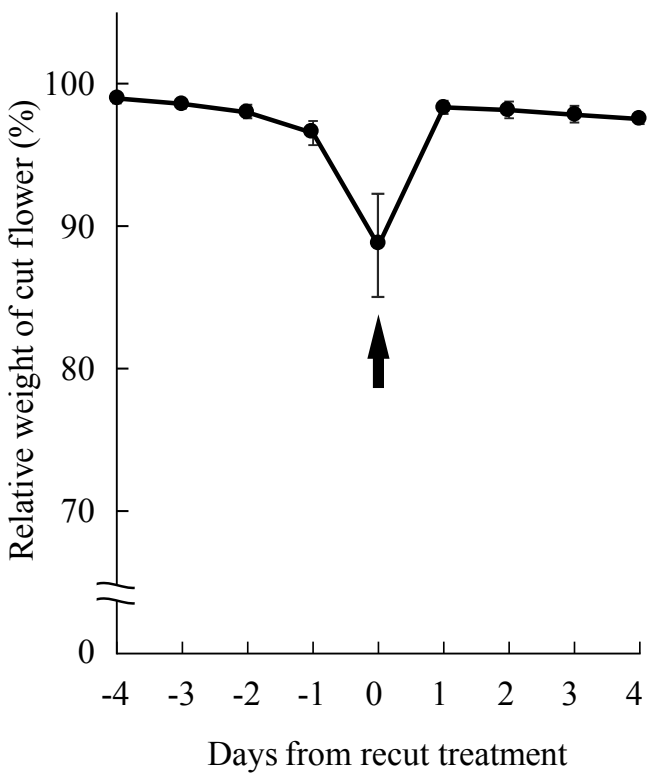

Fig. 4. Changes in the relative weights before and after the recut treatment of cut flowers harvested at stage 4 . The weight of the cut flowers was measured every day, and relative weights of cut flowers to those of harvest day were calculated. Weights of the stem ends were recorded and added to the weight of cut flowers after the recut treatment. The arrow indicates recut treatment. Bars indicate $\pm \operatorname{SE}(\mathrm{n}=3)$.

end restored the weight of the cut flowers on the next day of treatment (Fig. 4).

\section{Discussion}

The antique-stage cut flowers of 'Endless Summer', 'Glowing Alps', 'Grünherz', 'Masja', 'Temari Ezo', and line No. 2 exhibited significantly longer vase lives than fresh-stage cut flowers (Table 1). The antiquestage cut flowers of some cultivars exhibited vase lives 
almost identical to those of fresh-stage cut flowers. Market staff and growers of cut hydrangea flowers often hypothesize that antique-stage cut hydrangea flowers have longer vase lives than fresh-stage cut hydrangea flowers (Kitamura, 2016). However, they appear to possess no information regarding the differences in vase lives among cultivars. Screening of the cultivars would be required to produce antique-stage cut hydrangea flowers that exhibit longer vase lives than freshstage cut hydrangea flowers. Since there was no correlation between the vase lives of fresh- and antiquestage cut flowers, we must wait for the transition to the antique-stage when conducting cultivar screening.

The number of decorative florets is a major factor in determining the vase lives of cut hydrangea flowers, and cut flowers bearing fewer decorative florets exhibit long vase lives (Kitamura and Ueno, 2015). The number of decorative florets of antique-stage cut flowers was almost identical to that of fresh-stage cut flowers, and the effect of the difference in the number of decorative florets on the vase lives of the cut flowers harvested at these two stages does not require consideration (Table 1).

Analysis of the cut flower weight indicated that vessel occlusion in the stem end resulted in the softening of cut flowers harvested at stage 4 (Fig. 4). In a wide variety of cut flowers, vessel occlusion results in the disruption of water balance and wilting of cut flowers (Loubaud and van Doorn, 2004; van Doorn and Cruz, 2000; van Doorn et al., 1989). Thus, wilting or desiccation of the decorative sepals observed in the cut hydrangea flowers at other harvest stages may also have been due to the disruption of water balance caused by vessel occlusion in the stem ends. The difference between the timing of wilting of fresh-stage decorative sepals and the desiccation of antique-stage decorative sepals may reflect a difference in the frequency of vessel occlusion at the stem ends. The frequency of the disruption of water balance in the cut flowers of 'Xi'an' decreased after stage 2 (Fig. 3B). We reported previously that tracheid-like tissue developed in antique-stage decorative sepals (Kitamura et al., 2016). Development of conductive tissue in the decorative sepals may increase the tolerance for the water balance disruption that occurred after stage 2. In the cut flowers of 'Masja', the disruption of water balance frequently occurred not only in stage 1, but also in stage 2 (Fig. 3A). The difference between 'Xi'an' and 'Masja' indicated that the disruption in the water balance became suppressed at different harvest stages among cultivars.

Some fresh-stage cut flowers exhibited markedly longer vase lives than the average vase life in several cultivars and lines (Table 1). This wide variation in vase life in fresh-stage cut flowers could be explained by the coexistence of non-decorative floret flowering and decorative floret flowering stages in fresh-stage cut flowers. In 'Xi'an', cut flowers harvested at the decorative floret flowering stage (stage 2) showed significantly longer vase lives than those harvested at the nondecorative floret flowering stage (stage 1), and the difference in vase life was not significant when compared to the antique-stage (stage 4) (Fig. 3B). The difference between flowering stage 1 and 2 could also be important when considering the production of fresh-stage cut hydrangea flowers. Harvesting of cut flowers at the decorative floret flowering stage may increase the length of vase lives of fresh-stage cut hydrangea flowers. However, we should note that cut flowers of some cultivars, like 'Masja', harvested at the decorative floret flowering stage, have a relatively short vase life.

Some antique-stage cut flowers showed almost identical or shorter vase lives than fresh-stage cut flowers (Table 1). As suggested in the recut-treated antiquestage cut flowers, vessel occlusion in the stem ends caused the early termination of vase life in those cut flowers (Fig. 4). On the other hand, some cut flowers that exhibited markedly long vase lives developed roots at their stem ends (Table 1). Root development at the stem end prior to the disruption of water balance may have resulted in the markedly long vase lives observed in the cut flowers of 'Benton', 'Christmas', 'Masja', 'Xi'an', line No. 2, and line No. 3. Bacterial proliferation often causes vessel occlusion (Loubaud and van Doorn, 2004; van Doorn et al., 1989). Some factors causing bacterial proliferation may exist in the antiquestage cut flowers that had relatively short vase lives. Including antibacterial agents, some treatments that suppress vessel occlusion may be effective for maintaining a long vase life in cut hydrangea flowers.

The appearance of the cut flowers the end of vase life differed between the cultivars. Wilting indicated the end of vase life for most fresh-stage cut flowers (Table 2). This suggested that water balance disruption was the major factor in the termination of vase life in the freshstage cut flowers as discussed above. In 'Madame Emile Mouillere', 'Masja', 'Xi'an', line No. 2, and line No. 5, browning of decorative sepals was frequently observed at the end of vase life in fresh- and/or antiquestage cut flowers (Table 2). Sensitivity to browning may also be a factor for cultivar differences in vase life in both stages. Sepal desiccation without shrinking indicated the end of vase lives for most antique-stage cut flowers (Table 2). Decorative organs in Helichrysum bracteatum do not shrink even after desiccation as a result of physical reinforcement by the secondary cell wall (Nishikawa et al., 2008). Under periodic mist conditioning, excised fresh-stage and antique-stage decorative sepals of hydrangea rot almost completely, but the veins remain unaffected in antique-stage decorative sepals. This observation suggests the existence of some reinforcement in the vascular tissue of antique-stage decorative sepals. It is possible that the vase life extension observed in antique-stage cut flowers was a false effect produced by the physical cell wall reinforcement 
of the tissue of decorative sepals. For example, the shrinking of decorative sepals caused by the disruption of water balance in antique-stage cut flowers may be compensated by the aforementioned reinforcement, which slowed the end of vase life. However, in 'Masja' and 'Xi'an', cut flowers harvested at the beginning of the decorative sepal greening stage (stage 3) exhibited relatively longer vase lives than those harvested at the antique-stage (stage 4) (Fig. 3). The physical reinforcement of decorative sepals is not completed at that stage, suggesting that some other mechanism for vase life extension exists in addition to the physical reinforcement of decorative sepals (Kitamura et al., 2016).

In conclusion, a relatively longer vase life could be expected when cut hydrangea flowers are harvested after flowering of the decorative florets. However, we should note that the cut flowers of 'Masja' harvested at the decorative floret flowering stage had relatively short vase lives. The disruption of water balance caused by vessel occlusion in the stem ends may be a factor leading to the end of vase life of cut hydrangea flowers. Therefore, treatments that suppress vessel occlusion may be effective to extend the vase life of cut hydrangea flowers.

\section{Acknowledgement}

The authors thank The Horticulture Journal reviewers and the editor for helping to improve this paper.

\section{Literature Cited}

Kitamura, Y. 2016. Production of cut hydrangea flower. p. 93102. In: Nosangyosonbunkakyoukai (ed.). Recent Techniques in Floriculture. Series 8 (In Japanese). Nosangyosonbunkakyoukai, Tokyo.

Kitamura, Y. and S. Ueno. 2015. Inhibition of transpiration from the inflorescence extends the vase life of cut hydrangea flowers. Hort. J. 84: 156-160.

Kitamura, Y., Y. Kato, T. Yasui, H. Aizawa and S. Ueno. 2017a. Relation between increases in stomatal conductance of decorative sepals and the quality of antique-stage cut hydrangea flowers. Hort. J. 86: 87-93.

Kitamura, Y., T. Uemachi and Y. Kato. 2017b. Non-decorative floral organs largely contribute to transpiration and vase life of cut hydrangea flowers with lacecap inflorescence. Hort. J. 86: 263-268.

Kitamura, Y., T. Watanabe, K. Kametani and W. W. Teoh. 2016.
Cells with secondary cell wall and pits observed in the antique-stage decorative sepals of Hydrangea spp.. Hort. Res. (Japan) 15 (Suppl. 2): 465 (In Japanese).

Loubaud, M. and W. G. van Doorn. 2004. Wound-induced and bacteria-induced xylem blockage in roses, Astilbe, and Viburnum. Postharvest Biol. Technol. 32: 281-288.

Mega, K. 1957. Water absorption and transpiration of cut flowers. Bull. Univ. Osaka Pref. 7: 15-22.

Melo, N., R. M. Tavares, F. Morais, J. G. Barroso and M. S. S. Pais. 1995. Lipid composition of thylakoid membranes from leaves and regreened spathes of Zantedeschia aethiopia. Phytochemistry 40: 1367-1371.

Nishikawa, N., H. Ito, T. Awano, M. Hosokawa and S. Yazawa. 2008. Characteristic thickened cell walls of the bracts of the 'Eternal Flower' Helichrysum bracteatum. Ann. Bot. 102: 31-37.

Salopek-Sondi, B., M. Kovac, N. Ljubesic and V. Magnus. 2000. Fruit initiation in Helleborus niger L. triggers chloroplast formation and photosynthesis in the perianth. J. Plant Physiol. 157: 357-364.

Salopek-Sondi, B., M. Kovac, T. Prebeg and V. Magnus. 2002. Developing fruit direct post-floral morphogenesis in Helleborus niger L. J. Exp. Bot. 53: 1949-1957.

Schmitzer, V., M. M. Petkovsek and F. Stampar. 2013. Sepal phenolic profile during Helleborus niger flower development. J. Plant Physiol. 170: 1407-1415.

Tavares, R. M., F. Morais, N. Melo and M. S. S. Pais. 1998. Thylakoid membrane reorganization during Zantedeschia aethiopia spathe regreening: consequence of the absence of $\Delta^{3}$-trans-hexadecenoic acid in photochemical activity. Phytochemistry 47: 979-984.

Uemachi, T. and T. Nishio. 2005. Relationship between the inflorescence structure and setting of decorative flowers on lacecap cultivars of Hydrangea macrophylla (Thunb.) Ser. and H. serrata (Thunb.) Ser. Hort. Res. (Japan) 4: 435-438 (In Japanese with English abstract).

Uemachi, T., M. Kurokawa and T. Nishio. 2006. Comparison of inflorescence composition and development in the lacecap and its sport, hortensia Hydrangea macrophylla (Thunb.) Ser. J. Japan. Soc. Hort. Sci. 75: 154-160.

van Doorn, W. G. and P. Cruz. 2000. Evidence for a woundinginduced xylem occlusion in stems of cut chrysanthemum flowers. Postharvest Biol. Technol. 19: 73-83.

van Doorn, W. G., K. Schurer and Y. de Witte. 1989. Role of endogenous bacteria in vascular blockage of cut rose flowers. J. Plant Physiol. 134: 375-381.

Yoshida, K., D. Ito, Y. Shinkai and T. Kondo. 2008. Change of color and components in sepals of chameleon hydrangea during maturation and senescence. Phytochemistry 69: 3159-3165. 